\title{
CONSTRUÇÃO E APLICAÇÃO DE MODELO METODOLÓGICO COM BASE NA TRÍPLICE MIMESE DE RICOEUR
}

\author{
CONSTRUCTION AND APPLICATION OF A METHODOLOGICAL MODEL BASED \\ ON RICOEUR'S TRIPLE MIMESE
}

\author{
Carolina de Moraes Souzaํㄹ e Francilaine Munhoz de Moraes² \\ 1 Universidade de Coimbra, Faculdade de Letras, Portugal, e-mail: cmoraesouza@gmail.com \\ 2 Universidade de Brasília, Faculdade de Comunicação, Brasil, e-mail: moraesfranci@yahoo.com.br
}

\author{
ART ICLE INFO \\ Article history: \\ Received 2020-01-15 \\ Accepted 2020-04-10 \\ Available online 2020-04-10
}

Palavras-chave: Metodologia qualitativa. Tríplice mimese. Memória. Narrativa. Peregrinação.

Keywords: Triple mimesis. Pilgrimage. Memory. Media narrative. Qualitative methodology.

RESUMO. Este artigo expõe o processo de construção e aplicação de um modelo metodológico operaconalizado a partir da tríplice mimese de Ricoeur (1994), compondo os processos narrativos de préfiguração (mimese I), configuração (mimese II) e refiguração (mimese III). O desenho metodológico, de abordagem qualitativa, foi aplicado em estudo sobre narrativas acerca do fenômeno social da peregrinação e suas memórias. $O$ corpus abrange narrativas jornalísticas sobre os caminhos de Santiago de Compostela coletadas em reportagens publicadas em jornais brasileiros (Estado de São Paulo e Folha de São Paulo) e portugueses (Público e Correio da Manhã), e narrativas de peregrinos coletadas por meio da aplicação de questionário. Transmissão da memória coletiva, atualização das memórias dos grupos, bem como as representações para a memória associada ao fenômeno da peregrinação são abordagens da investigação. Os resultados revelam que a perspectiva qualitativa da pesquisa possibilitou interpretações de realidades sociais. As conclusões indicam que o modelo metodológico apresentado permite investigar fenômeno social em acontecimentos narrativos.

ABSTRACT. This paper exposes the process of construction and application of a methodological model based on Ricoeur's triple mimesis (1994), composing the narrative processes of pre-figuration (mimesis I), configuration (mimesis II) and refiguration (mimesis III). The methodological design, with qualitative approach, was applied in a study about narratives about the social phenomenon of pilgrimage and its memories. The corpus encompasses journalistic narratives about the paths of Santiago de Compostela collected in reports published in Brazilian (Estado de São Paulo and Folha de São Paulo) and Portuguese (Público and Correio da Manhã) newspapers, and pilgrim narratives collected through the application of quiz. Transmission of collective memory, updating of group memories, as well as representations for memory associated with the phenomenon of pilgrimage are approaches of the investigation. The results reveal that the qualitative perspective of the research enabled interpretations of social realities. The conclusions indicate that the presented methodological model allows to investigate social phenomenon in narrative events.

\section{Introdução}

A pesquisa investiga o fenômeno social da peregrinação a Santiago de Compostela e suas memórias coletivas em processo de pré-figuração, configuração e refiguração proposto pela tríplice mimese da narrativa de Ricoeur (1994). O objetivo deste artigo é apresentar o 
quadro metodológico construído com base em Ricoeur (1994). O modelo metodológico aliado ao construto teórico permite responder à pergunta de pesquisa: Como a mídia atualiza (refigura) as narrativas das peregrinações a Santiago de Compostela? Paralela a essa questão principal, a pesquisa investiga como as memórias se encontram presentes nas narrativas peregrinas. O estudo esquematizado observa as relações entre memória e narrativa e, por conseguinte, as memórias narrativas das peregrinações como fenômenos sociais.

A narrativa enquanto representação das ações do homem ao longo do tempo foi estudada por Ricoeur (1994). Para o autor, os textos são mimeses da realidade, reproduzidos de forma imaginativa e representativa, capazes de articular as partes em um todo. No entanto, a mimese narrativa não é uma réplica do real, a ela compete produzir algo novo que inclui aspectos éticos e estéticos dos atos humanos. Dessa forma, a narrativa sob a perspectiva da representação mimética assume, ao mesmo tempo, a função de ruptura com o referente e a função de mudança metafórica do campo prático para o texto. Assim, segundo Ricoeur (1994), o autor da narrativa não reproduz um decalque da realidade, mas inaugura um como se, em uma construção da construção.

Como proposta metodológica, portanto, este artigo utiliza a hermenêutica ricoeuriana. Como afirma Thompson (2011, p. 357), "a hermenêutica também se presta a ser um caminho metodológico, onde e quando o ser histórico se sujeita a demonstrar seus próprios caminhos de compreensão e interpretação". Pela interpretação hermenêutica é possível articular e reelaborar historicamente os sentidos e os significados da compreensão humana.

\section{Peregrinação a Santiago de Compostela}

A peregrinação consiste em práticas culturais e históricas que originalmente possuíam finalidade atrelada à religiosidade, mas que atualmente assumem características de jornada física e espiritual na qual pressupõe uma busca a partir do deslocamento ritualístico e, por vezes, sagrado. Para Steil (2003), as peregrinações incorporam diversos discursos e visões de mundo, nas quais compõem os seus rituais, em uma combinação de pessoas, textos e lugares. Tal combinação se caracteriza também por ser um ponto de identidade na peregrinação que oferece poder de autoridade a esse acontecimento. Ainda segundo o autor, elementos como pessoa, lugar e texto se apresentam como "depositários de tradições míticas e históricas atualizadas por seus peregrinos e demais agentes religiosos mediante a invocação de suas crenças, a veneração de suas imagens e a performance de seus rituais" (STEIL, 2003, p. 47).

Os Caminhos de Santiago estão entre as três principais rotas de peregrinação cristã desde o século IX - as outras têm como destino Roma e Jerusalém - e, após um período de declínio de popularidade, voltaram a adquirir grande número de adeptos nos anos 1980 e 
1990. Os Caminhos de Santiago tornaram-se o Primeiro Itinerário Cultural Europeu em 1987 e Património da Humanidade, na Espanha, em 1993, e na França, em 1998 (UNESCO, 2019).

A partir dos anos 1980, os Caminhos reúnem peregrinos com motivações diversas dentre os coletados em questionário neste trabalho, destacam-se: o caminhar com sentido espiritualista e de realização pessoal, melhoraria das aptidões físicas, turismo de lazer e aventura, conhecer e fazer amigos - além e aquém do motivo original voltado ao culto de Santiago Maior, um dos apóstolos de Jesus Cristo. Em 2016, a Oficina de Acogida del Peregrino de Santiago de Compostela - local de acolhimento dos peregrinos que chegam ao destino da peregrinação à Santiago de Compostela, vinculado à Catedral de Santiago e responsável pela concessão do último selo na Credencial de Peregrino e da Compostela registrou a chegada de mais de 200 mil peregrinos, de mais de 140 nacionalidades diferentes (OFICINA DE ACOGIDA DEL PEREGRINO, 2016).

Os caminhos de Santiago edificaram-se a partir da história, segundo a Igreja Católica, do translado dos restos mortais de Apóstolo Tiago da Palestina à região de Hispania, nome dado pelos romanos à Península Ibérica, atuais Portugal, Espanha, Andorra, Gibraltar e uma pequena parte a sul da França. Para Caballero (2011), a tradição sustenta que Santiago Maior foi a Hispania com o objetivo de pregar a mensagem de Cristo, mas ao retornar a Palestina foi morto e se tornou o primeiro apóstolo mártir. Seus restos mortais foram levados por discípulos de volta ao mundo romano ocidental, chegando até a Gallaecia - região localizada no Noroeste da antiga Hispania, corresponde aproximadamente ao da moderna região do norte de Portugal e da Galiza, Astúrias e Leão na Espanha - e descobertos após a invasão muçulmana por Teodomiro, bispo de Iria Flavia, paróquia civil da Galiza, Espanha, que foi sede episcopal cristã no Baixo Império Romano, durante os períodos suevo e visigótico, cuja sede da diocese foi transferida por Afonso II das Astúrias (791842) para Santiago de Compostela (CABALLERO, 2011). No reinado de Alfonso III, século VII, a crença e culto à sepultura de Santiago se consolidou e se legitimou na cidade de Compostela, com a obra Breviarum Apostolorum - texto latino que contém uma coleção de pequenas biografias e dados sobre os apóstolos de Jesus, entre eles seus lugares de pregação, sendo a fonte mais antiga que faz alusão à peregrinação. Caballero (2011) afirma que o Caminho de Santiago teve muita repercussão no mundo medieval hispânico, pois as autoridades buscaram benefícios políticos e socioeconómicos que se estenderam em um processo de consolidação e dinamização da monarquia leonesa, tendo a sede compostelana como um símbolo da elevada dignidade eclesiástica no contexto da Reforma Gregoriana e Cluníacas.

O desenvolvimento e história dos mais diversos caminhos (Português, Francês, Sanabrés, Inglés, do Norte, Primitivo, Finisterra, Via da Prata) demonstram a atualização da tradição cristã como forma de veneração jacobeia até os múltiplos sentidos e motivos que impulsionam atualmente os peregrinos a realizarem algum dos Caminhos. A tradição de 
caminhar tendo como meta o sepulcro do apóstolo se iniciou na Idade Média e hoje apresenta renovadas representações para a memória associada ao processo peregrinatório (MORENO, 1992).

A relação entre os peregrinos e o passado pode ser analisada, segundo Colemam (2012), por meio das perspectivas e práticas que sugerem a referenciação da memória e da tradição passíveis de recuperação de acontecimentos históricos no presente. Sánchez y Sánchez e Hesp (2015) destacam que o fenômeno da peregrinação revelou tanto no medievo como na era contemporânea uma ligação com a memória e a tradição (que não é necessariamente religiosa) no qual se destaca a problematização de conceitos modernos como identidade e memória coletiva no processo de transformação. Dentre as perspectivas possíveis, este trabalho investiga as relações entre memoria e narrativa.

\section{Memória e narrativa}

As sucessões de lembranças se alteram pelas mudanças produzidas nos meios coletivos, de forma que as unidades de recordação se transformam em multiplicidade de lembranças (HALBWACHS, 1990; POLLAK, 1992). A memória coletiva é, dessa forma, uma memória orgânica do indivíduo que opera no âmbito sociocultural e, também, uma possibilidade de criação de uma versão compartilhada do passado, resultado da interação entre membros do grupo, da comunicação social e, especificamente, da mídia.

Como coloca Casalegno (2006), dividir uma memória é compartilhá-la em conjunto e é por meio da narrativa que conseguimos restituir as experiências. Dessa forma, a narrativa assume caráter fundador, pois, além de suplente da experiência compartilhada, é também participante da fundação da memória coletiva. Uma memória comum se forma a partir das informações enviadas por membros de um grupo social que nutrem um sistema único, por meio da narrativa.

Ao citar a narrativa noticiosa, Ricoeur (1994) articula a sedimentação de padrões existentes anteriores à novidade. Segundo o autor, a ligação entre a tradição e os esquemas narrativos de conhecimento do narrador e do leitor, possibilita notar e entender o desvio, a inovação, o que surge de novo. A existência da novidade, característica primeira da narrativa jornalística, só é possível se constituir a partir de uma base cultural que gera no receptor da mensagem as expectativas impostas pelo narrador no processo de mediação.

Nora (1993) explica que, na sociedade contemporânea - preocupada com o apego à vida simbólica -, há uma necessidade de criar lugares, físicos ou simbólicos, com o objetivo de externalizar a memória compartilhada. Para o autor, esses locais surgem para que se mantenham tradições, garantindo a identificação do ato e do sentido da experiência do passado. Dessa forma, nota-se, nas narrativas memoriais, a presença de símbolos, signos e significados que remetem aos lugares de memória que incentivam o desenvolvimento de 
rastros e restos como marcos testemunhais do passado. Nesse contexto, Candau (2011) afirma que os conceitos de memória e identidade são indissociáveis das noções contemporâneas de lugares de memória e patrimônio. Para o autor, "o patrimônio é menos um conteúdo que uma prática de memória, obedecendo a um projeto de afirmação de si mesma" (CANDAU, 2011, p. 163). Nesse viés, essas ideias sedimentam a base teórica da investigação cujo desenho metodológico apresentamos a seguir.

\section{Desenho Metodológico}

O modelo metodológico aplicado na pesquisa foi operacionalizado com base nas ideias conceituais da tríplice mimese de Ricoeur (1994). Apresentamos, nesta seção, os conceitos teóricos que constituem a tríplice mimese, o corpus da investigação e o modelo metodológico, os quais instrumentalizaram o desenho metodológico.

\subsection{Tríplice mimese}

Segundo Ricoeur (1994), a intriga, em sua composição, apresenta raízes em uma précompreensão do mundo e da ação, quais sejam: pré-compreensões das estruturas inteligíveis, das fontes simbólicas e do caráter temporal. Essas características correspondem a mimese $\mathrm{I}$. O traço estrutural da intriga diz respeito às próprias formas narrativas mais caras a uma determinada sociedade, que compreende um conjunto de regras consideradas pertinentes a um bom modo de narrar ou a uma tradição narrativa. Ou seja, a intriga se baseia em conceitos comuns, concepções básicas que movimentam a vida humana.

Dessa forma, como afirma Ricoeur:

(...) qualquer narrativa pressupõe, da parte do narrador e de seu auditório, uma familiaridade com termos tais como agente, fim, meio, circunstâncias, socorro, hostilidade, cooperação, conflito, sucesso, fracasso etc... Nesse sentido, a frase narrativa mínima é uma frase de ação da forma $X$ faz $A$ nestas ou naquelas circunstâncias e levando em conta o fato de que $Y$ faz $\mathrm{B}$ em circunstâncias idênticas ou diferentes. Finalmente as narrativas tem como tema o agir e o sofrer (RICOEUR, 1994, p. 90).

No entanto, o autor adverte que a narrativa não se limita ao pré-entendimento da trama conceitual da ação, pois também há características discursivas que tem como função criar ou escolher as modalidades de discurso que são dignos de serem chamados de narrativa. Nesse sentido, Ricoeur (1994) se referere às questões do estilo, pois, mais do que contar uma história, o texto, por via da sintaxe e de sua dicção, estabelece um padrão que nos permite chamá-lo de narrativo e não de um conjunto de ações. Assim, a linguagem estabelece a instância narrativa. Dessa forma, para o autor, compreender uma história é também entender, em simultâneo, a linguagem do fazer e a tradição cultural das formas (regras) das intrigas.

Existem elementos - responsáveis pela constituição da tradição cultural da narrativa - capazes de responder perguntas como: "quem? onde? por quê? o quê? como? para quê? 
com quem? contra quem?" (RICOEUR, 1994, p. 55). Esses elementos são: (1) metas: dizem respeito às finalidades das ações, representam também uma expectativa de futuro inserida na ação; (2) motivos: os agentes são movidos por crenças, desejos, intenções e convicções que estimulam o fazer; (3) agente: aquele que realiza a ação; (4) circunstâncias: uma ação não ocorre isoladamente, ela se encontra inserida em suas circunstâncias; (5) interação: as ações se apresentam socialmente e, por isso, assumem um caráter relacional; (6) desfecho: uma ação é sempre levada a um sentido de fim, a um fechamento. Este trabalho propõe, como ferramenta metodológica, identificar as relações da trama nos eventos narrativos.

O traço simbólico da mimese I se revela por um conjunto de mitos, crenças, valores, questões éticas e morais, enfim, uma ampla gama de manifestações típicas da cultura. $A$ composição da intriga está conectada a processos culturais que articulam a experiência incorporando esta à ação, oferecendo legibilidade e regras de valor. Os traços simbólicos da pré-compreensão comandam quais aspectos do fazer, do poder-fazer e do saber-poder-fazer pertencem à transposição poética.

Nesse entendimento, uma ação só pode ser narrada porque em algum momento, por meio da articulação de signos, regras e normas ela foi simbolicamente mediatizada. Por mediação simbólica, entende o autor, um conjunto de símbolos que embasam a ação a ponto de constituir um sentido consensual - neste trabalho consideramos signos e símbolos termos equivalentes, cujo sentido consensual ocorre quando os símbolos ou os signos são de pleno conhecimento do narrador e do leitor. "Assim, antes de serem submetidos à interpretação, os símbolos são interpretantes internos da ação" (RICOEUR, 1994, p. 93). Essas normas articulam os signos disponíveis como forma de garantir que a ação passe por uma avaliação e justificação, relacionadas aos aspectos éticos da experiência. Tais aspectos, que se manifestam por meio de recursos simbólicos, sugestionam a impossibilidade de neutralidade nas ações humanas. O comprometimento ético é parte integrante da negociação dos significados nas narrativas.

Quanto ao traço temporal, Ricoeur (1994) ressalta que eles permanecem implícitos às mediações simbólicas e revelam o intercâmbio entre as dimensões temporais do presente, passado e futuro em uma estrutura de intratemporalidade, pressupondo o ser no tempo. $O$ autor explica que analisar essa intratemporalidade é perceber mais do que uma simples sucessão de agoras, é entender fatos, circunstâncias, falas, pessoas e sentimentos encadeados em uma lógica temporal que vai de um começo a um fim.

Para isso, o autor sugere que sejam observadas as unidades lógicas menores, chamadas de incidentes narrativos, que são unidades temporais com significado distribuídas em sucessão na medida em que se manifestam os acontecimentos ligados ao todo narrativo. Cada uma dessas unidades menores está vinculada a uma ação principal, responsável por integrá-las aos elementos da trama conceitual. A articulação desses incidentes representa as mudanças ocorridas no desenvolvimento da experiência. Cada nova unidade evidencia um 
passo dado no seguimento das experiências relatadas e enfatiza um aspecto significativo para o entendimento da história.

Assim, o tempo prefigurado (mimese I) se apresenta como o posicionamento da experiência em determinados contextos que constituem os espaços ou cenários da experiência (locus de memória). Compreender como esses cenários se compõem narrativamente é identificar como os indivíduos interpretam as relações históricas e culturais que informam suas experiências sociais, analisando as articulações entre essas relações e o desenvolvimento dessas experiências.

A mimese II, para o autor, representa a fase de mediação da prefiguração do campo prático para a refiguração na recepção da obra, ou seja, representa o processo de configuração textual. A função mediadora dessa fase origina-se da dinamicidade do processo de configuração. Esse dinamismo ocorre porque a intriga exerce no campo textual a função de integração.

Na mimese II, os elementos presentes na mimese I assumem um formato, no qual o 'como se' ganha protagonismo e o 'por que' deixa de ser uma pergunta implícita para se tornar uma explicação concreta das ações no desenrolar da narrativa. E é por isso que essa mimese é responsável por ligar os acontecimentos individuais à história como um todo.

A história também não se apresenta como uma simples sucessão de acontecimentos singulares, ela é capaz de construir um tema ou uma matéria, que o autor chama de síntese do heterogêneo, na qual há a mistura de coisas distintas em uma lógica generalizante. Dessa forma, a intriga compõe fatores como metas, motivos agentes, meios, interações, circunstâncias e desfechos de modo generalizante.

A intriga é, portanto, tecida pela combinação de duas dimensões temporais: a cronológica (ou episódica) e a não-cronológica (configurante). A primeira trata dos acontecimentos, da sucessão dos episódios no desenvolvimento da narrativa, ou seja, revela como os episódios levam a conclusão. A não-cronológica se refere à sucessão de acontecimentos em uma totalidade significante, na qual a narrativa inteira pode ser resumida em tema.

O autor ainda considera o par de conceitos esquematismo e tradicionalismo como uma composição da relação específica com o tempo. O esquematismo é o que torna a obra inteligível, pois seu caráter sintético agrega entendimento e intuição. É aquele elemento que possibilita - por meio da constituição do tema - o entendimento das mudanças do porvir e prevê o desfecho das narrativas. Já o tradicionalismo refere-se à "uma história que tem todas as características de uma tradição" (RICOEUR, 1994, p. 107).

A mimese III é responsável, pois, por estabelecer as marcas de aproximação entre o mundo do texto e o mundo do leitor. Ricoeur, a partir do pressuposto que a investigação está na relação entre tempo e narrativa, aborda o mundo do leitor na perspectiva de que "a 
narrativa tem seu sentido pleno quando é restituída ao tempo do agir e do padecer em mimese III" (Ricoeur, 1994, p. 110). Essa restituição se dá no ato da leitura.

O processo de refiguração, no qual está a mimese III, reinventa a intriga por meio de sua própria compreensão. Ou seja, por meio do entendimento do texto configurado, o leitor constrói sua identidade - em contraste com a dos outros -, estabelece reconhecimentos e compara situações para elaborar uma visão de si mesmo, do mundo e do outro, acrescentando algo de sua identidade à 'nova' intriga.

Para Ricoeur (1994), portanto, os conceitos esquematização e tradicionalismo mostram a importância de analisar a narrativa sem as barreiras deterministas do que está fora e do que está dentro do texto. A leitura faz acontecer, concomitante ao seu ato, a configuração da narrativa. Ricoeur chama essa possibilidade de atualização (1994, p. 118). As narrativas apresentam experiências e expectativas a partir das quais se estabelecem diferentes relações com o texto, sendo uma das formas pelas quais a leitura atualiza o texto.

Dessa forma, segundo o autor, a análise de um texto deve compreender o novo espaço produzido entre o mundo do texto e o horizonte de seus possíveis leitores. A leitura pode ser considerada, em alguma medida, a imitação da imitação, pois possibilita, a partir do configurado, o deslocamento. A promessa de significação, portanto, concretiza-se na interpretação. Logo após adquire um novo significado que já não necessariamente coincide com o pretendido inicialmente. $O$ ato da leitura é, assim, responsável por aglutinar todos os momentos miméticos e ampliar o conjunto de significados que define uma realidade. Ressaltamos que essas ideias consubstanciam a construção do modelo metodológico aplicado na pesquisa.

\subsection{Corpus de pesquisa}

O corpus analítico da pesquisa abarca dois grupos de textos sobre as peregrinações a Santiago de Compostela. O primeiro (G1) recai sobre narrativas jornalísticas publicadas na mídia noticiosa e o segundo (G2) sobre as narrativas dos peregrinos coletadas em entrevistas. Vale enfatizar que, dado o objetivo do artigo, as narrativas jornalísticas (G1) constituem o corpus principal e as narrativas dos peregrinos (G2) constituem o corpus complementar.

Foram selecionados para o primeiro grupo (G1) quatro reportagens online: duas de jornais brasileiros (Estado de São Paulo e Folha de São Paulo) e duas de jornais portugueses (Público e Correio da Manhã). A peça 1 refere-se à reportagem "Epopeias Próprias" publicada em especial do jornal Estado de São Paulo. A peça 2, "Como fazer o Caminho de Santiago de Compostela fugindo dos clichês? ", foi publicada na editoria de Turismo do jornal Folha de São Paulo. A peça 3, "Alemães empurram Caminho de Santiago para junto do mar", foi publicada no jornal Público e a peça 4, "Pelos caminhos de Santiago", foi publicada na editoria Destinos do jornal Correio da Manhã Boa-Vida. Os critérios de seleção das reportagens do primeiro grupo (G1) foram: textos jornalísticos que tem como tema principal a peregrinação 
de Santiago e seus caminhos, para que as análises pudessem representar corretamente os objetivos do trabalho; narrativas publicadas em jornais de grande expressão no Brasil e em Portugal, com alto número de leitores e assinantes; reportagens online para facilitar o acesso e busca; as duas nacionalidades de língua portuguesa mais presentes no caminho de Santiago são a brasileira e portuguesa, por isso, textos retirados de jornais brasileiros e portugueses.

O segundo grupo (G2) abarca as repostas dos peregrinos às questões colocadas por meio da aplicação de um questionário, que retratam o discurso dos peregrinos sobre o final do processo - mimese III - de construção narrativa da peregrinação. O questionário foi aplicado em grupos do Facebook relacionados ao Caminho de Santiago com maior número de membros na língua portuguesa. São eles: Caminho de Santiago para mulheres; Caminho de Santiago de Compostela de Bicicleta; a Caminho de Santiago; Caminhos de Santiago de Compostela; Caminho Português Interior de Santiago. Os peregrinos foram convidados a participar por meio de postagens nesses grupos, com o link para responder o questionário online (formulários do Google). As narrativas correspondem as respostas de 35 peregrinos que realizaram o caminho entre os anos 2000 e 2018. O período temporal (18 anos) foi determinado com base na idade dos membros dos grupos nos quais o questionário foi aplicado.

Os textos do G1 foram analisados sobre os aspectos da mimese I e mimese II, no G2 foram analisados aspectos da mimese III, aspectos sistematizados em modelo de análise em três etapas exposto a seguir.

\subsection{Modelo metodológico}

Com base na tríplice mimese de Ricoeur (1994) e suas relações com os constructos teóricos, apresentamos o modelo metodológico desta pesquisa.

A tabela 1 demonstra as três etapas de análise do corpus dividido em dois grupos: o primeiro grupo engloba as narrativas midiáticas representadas pelas reportagens de jornais, analisados nas etapas mimese I e mimese II; o segundo corresponde à narrativa dos peregrinos, pesquisados na etapa mimese III. A tabela abaixo mostra o modelo de análise detalhado por etapa e os objetivos para o desenvolvimento da investigação do corpus. 
Tabela 1 - Modelo de análise em três etapas

\begin{tabular}{|c|c|c|c|}
\hline $\begin{array}{c}\text { Mimese } \\
\text { (Etapa) }\end{array}$ & $\begin{array}{c}\text { Mimese I } \\
\text { (prefiguração) }\end{array}$ & $\begin{array}{c}\text { Mimese II } \\
\text { (configuração) }\end{array}$ & $\begin{array}{l}\text { Mimese III } \\
\text { (refiguração) }\end{array}$ \\
\hline $\begin{array}{l}\text { Do que se } \\
\text { trata? }\end{array}$ & $\begin{array}{l}\text { Pré-compreensão da narrativa da } \\
\text { peregrinação }\end{array}$ & A narrativa midiática & $\begin{array}{l}\text { A visão dos peregrinos } \\
\text { refigurada pela narrativa } \\
\text { midiática }\end{array}$ \\
\hline $\begin{array}{l}\text { Como } \\
\text { fazer? }\end{array}$ & $\begin{array}{l}\text { Observar no texto midiático: } \\
\text { 1. A estrutura da narrativa } \\
\text { 2. Os recursos simbólicos } \\
\text { da narrativa } \\
\text { 3. A unidades temporais } \\
\text { representadas por } \\
\text { expressões de tempo e } \\
\text { marcadores temporais }\end{array}$ & $\begin{array}{l}\text { Observar no texto midiático: } \\
\text { 1. Os acontecimentos } \\
\text { jornalísticos que } \\
\text { propõem a refiguração } \\
\text { (atualização) da } \\
\text { narrativa } \\
\text { 2. Os símbolos, locais, } \\
\text { histórias e memórias } \\
\text { mantidas pela narrativa }\end{array}$ & $\begin{array}{l}\text { Observar na } \\
\text { interpretação do } \\
\text { peregrino: } \\
\text { 1. } \text { Se e como as } \\
\text { narrativas foram } \\
\text { refiguradas } \\
\text { 2. A relação entre o } \\
\text { discurso do } \\
\text { peregrino e a } \\
\text { narrativa midiática } \\
\text { O contexto da } \\
\text { motivação e } \\
\text { resultado da } \\
\text { peregrinação e a } \\
\text { relação com a } \\
\text { memória }\end{array}$ \\
\hline $\begin{array}{l}\text { Com qual } \\
\text { objetivo? }\end{array}$ & $\begin{array}{l}\text { Observar as pré-concepções da } \\
\text { narrativa da peregrinação; notar } \\
\text { os símbolos coletivos; perceber } \\
\text { as identidades vinculadas às } \\
\text { narrativas. }\end{array}$ & $\begin{array}{l}\text { Perceber se e como esses } \\
\text { acontecimentos midiáticos } \\
\text { renovam a narrativa se e como } \\
\text { reforçam as memórias. }\end{array}$ & $\begin{array}{l}\text { Notar as relações entre } \\
\text { as mimeses; o vinculo } \\
\text { entre a narrativa pré- } \\
\text { figurada, configurada e } \\
\text { a refigurada. }\end{array}$ \\
\hline
\end{tabular}

Fonte: SOUZA E MORAES (2019).

A tabela 1 descreve, na primeira linha (Do que se trata?), os seguintes elementos: mimese I (prefiguração), trata da pré-compreensão da narrativa da peregrinação como o préentendimento do mundo no texto da peregrinação; mimese II (configuração) trata da narrativa midiática como configuração da memória narrativa e o estimulo à atualização narrativa impulso à renovação por meio do acontecimento midiático; e a mimese III (refiguração) trata a visão dos peregrinos configurada pela narrativa midiática como leitura e o processo de renovação narrativa e a composição de memórias e atualizações.

Na segunda linha (Como Fazer?), na mimese I, observa no texto midiático: (1) a estrutura da narrativa (Como ela compõe termos heterogéneos que respondem às perguntas: O que? Quem? Por que? Como? Com ou contra-quem? Análise dos elementos: agente; metas e motivos; circunstâncias; interação; desfecho); (2) os recursos simbólicos da narrativa (entendimentos conjuntos de uma situação que funcionam como norma social que possuem caráter de avaliação e justificação); (3) as unidades temporais representadas por expressões de tempo e marcadores temporais (desenvolvem qualidades temporais presentes nas ações narradas e demonstram a relação entre o tempo e a ação que constroem a intriga). Ainda na segunda linha, na mimese II, observa no texto midiático: (1) os acontecimentos jornalísticos que propõem a refiguração (atualização) da narrativa; (2) os símbolos, locais, histórias e 
memórias mantidos pela narrativa. E, na mimese III, observa na interpretação do peregrino: (1) se e como as narrativas foram refiguradas; (2) a relação entre o discurso do peregrino e a narrativa midiática; (3) o contexto da motivação e resultado da peregrinação e a relação com a memória.

$\mathrm{Na}$ terceira linha (Com qual objetivo?), a mimese I observa as pré-concepções da narrativa da peregrinação, nota os símbolos coletivos e percebe as identidades vinculadas às narrativas; a mimese II percebe se e como esses acontecimentos midiáticos renovam a narrativa, se e como reforçam as memórias; a mimese III nota as relações entre as mimeses, o vínculo entre a narrativa pré-figurada, configurada e a refigurada. A perspectiva qualitativa deste modelo possibilitou os resultados apresentados a seguir.

\section{Resultados}

Os resultados da pesquisa revelaram que, nas narrativas jornalísticas e nas narrativas peregrinas, conforme Pollak (1992) e Halbwachs (1990), a memória se constitui como um instrumento de reconfiguração do passado, ou seja, um enquadramento do passado a partir das demandas do presente.

A verificação dos elementos da pré-figuração (mimese I) dos textos do grupo 1 (narrativa jornalística) denotaram que as metas, motivos, circunstâncias e interações são os principais responsáveis por revelar os vínculos da narrativa com as histórias da peregrinação. A interação entre agentes concretos e abstratos da narrativa evidencia como se desenvolve a vinculação das experiências entre os indivíduos e sua coletividade (HALBAWACHS, 1990; POLLAK, 1992; CASALEGNO, 2006). Percebeu-se, na mimese I, que há relação entre os agentes da narrativa e a memória da peregrinação, em processo de identificação do agente com o seu grupo social.

Os traços simbólicos evidenciam o uso dos signos linguísticos (conchas; setas amarelas; peregrino; cajado; patrimônio; cultura; Bom Caminho; Ultreia; Suseia; Compostela; Credencial do peregrino; ...) como forma de representação e caracterização de agentes, comportamentos e memórias na narrativa. Os traços temporais indicam a capacidade das narrativas jornalísticas de compor as três temporalidades: passado, presente e futuro. Com base nas análises empreendidas e amparo teórico percebeu-se que a memória, ainda que ancorada no passado, necessita do impulso do presente para ser incitada. De modo similar, a narrativa jornalística - baseada no relato do presente - é um meio de transmissão atualizada da memória coletiva. A narrativa jornalística reforça e também atualiza as memórias do fenômeno (peregrinação).

O exame das narrativas do corpus de pesquisa mostra que as memórias reforçadas pela narrativa jornalística se apresentam principalmente em forma de símbolos associados à 
história da peregrinação. Esses símbolos representam a identidade dos peregrinos construída ao longo do tempo.

Práticas, rituais e comportamentos específicos também foram observados nos textos em investigação. Dormir em albergues, carregar por muitos quilómetros os próprios pertences, abdicar do luxo, compartilhar o pouco que possui, fazer refeições com pessoas desconhecidas, desenvolver a compaixão e ajudar o próximo são alguns dos comportamentos que ainda se encontram presentes na memória da peregrinação, segundo as narrativas analisadas.

A mimese III (refiguração) foi representada pela visão dos peregrinos sobre as histórias, memórias, identidades, imagens e costumes associados à peregrinação. A narrativa peregrina demonstrou que a motivação e o resultado da realização do caminho guardam relação com os seguintes aspectos de memória estudados neste trabalho: a manutenção das memórias do caminho, observadas nas mimeses I e II; o apego às tradições, valores e costumes que mantém as pessoas conectadas às memórias e identidades. A narrativa dos peregrinos revelou que as principais mudanças - atualização ou refiguração - possuem relação com as questões da motivação para a realização do caminho, uma vez que as narrativas sobre as peregrinações são atualizadas a partir de novas perspectivas da memória.

\section{Considerações Finais}

Ao investigar a peregrinação a Santiago de Compostela notou-se que a mídia, por meio da narrativa jornalística, reforça e também atualiza as memórias do fenômeno (peregrinação). Com base em Coleman (2012), a investigação do grupo II notou que, em muitos casos, o que leva a pessoa a realizar a peregrinação é a necessidade de sentir a estabilidade do caminho em relação ao mundo e ao tempo. O caminhante adere aos valores de forma performativa à medida em que encarna a identidade do peregrino tanto individualmente quanto como pertencente ao grupo social dos peregrinos. Coleman alega que as narrativas da peregrinação funcionam como alegorias do que era feito no passado, de modo que tal repetição passa a ter um significado diferente do primeiro, apresentando nova carga interpretativa, influenciada pela sua realização no presente. Esses aspectos passam a integrar a ação do peregrino, quando por exemplo fazem caminhada seguindo os mesmos passos, passando pelos mesmos caminhos, usando os mesmos símbolos e rituais, porém sempre renovados.

A peregrinação foi observada - na forma proposta por Coleman (2003) - como uma interação entre pessoas, textos e lugares, nas quais as tensões entre as narrações tanto orais quanto escritas constroem uma forma peculiar de narrativa. Para os autores, quando o "evento teofânico originário é recontado, pode orientar as posteriores percepções dos peregrinos sobre um determinado lugar, assim como proporcionar muita da motivação para as suas 
viagens" (COLEMAN, 2003, p. 6). Assim, narrar sobre a peregrinação é, portanto, uma parte importante do retorno, permitindo que se reinterprete as experiências e simultaneamente se identifique como peregrino. Também é capacidade das narrativas de experiência inspirarem gerações futuras como guias práticos tanto para jornada física quanto para suas interpretações.

A pesquisa também revelou, amparado em Pollak (1992), que a memória é um componente de inserção identitária e uma ferramenta que gera o sentimento de continuidade e coerência de um grupo em constante processo de atualização. A referência ao passado é uma forma de manter a coesão e a estabilidade dos grupos e instituições de uma sociedade capazes de definir sua identidade, complementariedade, como também suas oposições. Assim, em conformidade com os autores, conclui-se que a velocidade dos tempos impele as sociedades a guardarem imagens do presente - por meio das narrativas, símbolos, rituais e outros locais de memória - para posterior consulta, demonstrando a necessidade dos indivíduos contemporâneos de se ancorarem em memórias que inspiram confiança e conforto.

Pelos resultados expostos, inferimos que a perspectiva qualitativa da pesquisa possibilitou interpretações de realidades sociais da peregrinação (BAUER, GASKELL E ALLUN, 2010). Consideramos que o desenho metodológico permite investigar fenômeno social em eventos narrativos. Desse modo, entendemos que o modelo apresentado pode contribuir com futuras investigações de abordagem qualitativa sobre estudos narrativos.

\section{Referências}

BAUER, M., GASKELL, G., ALLUN, N. Qualidade, quantidade e interesses do conhecimento. In: Pesquisa qualitativa com texto, imagem e som. Petrópolis: Vozes, 2010, p. 17-36.

CANDAU, J. Memória e identidade. Trad. Maria Leticia Ferreira. São Paulo: Contexto, 2011. CASALEGNO, F. Memória Cotidiana: Comunidades e comunicação na era das redes. Porto Alegre: Sulina, 2006.

COLEMAN, S. Memory as Absence and Presence: pilgrimage, archeology and the creativity of destruction. Journeys, n. 13, 2012, p. 1-20.

COLEMAN, S. Pilgrim Voices: authoring Christian Pilgrimage. In: Coleman, S; Elsner, J (ed.). Pilgrim Voices: narrative and authorship in Christian pilgrimage. New York: Oxford Berghahn Books, 2003.

HALBWACHS, Maurice. A memória coletiva. São Paulo: Editora Vértice, 1990.

MORENO, H. As peregrinações a Santiago e as Relações entre o norte de Portugal e a Galiza. I Congresso dos Caminhos Portugueses a Santiago de Compostela. Edições Távola Redonda, 1992. 
NORA, Pierre. Entre memória e história: a problemática dos lugares. Trad. Yara Aun Khoury. São Paulo: Projeto História. Revista do Programa de Estudos Pós-Garduados em História e do Departamento de História da PUC-SP, n. 10, 1993, p. 7-28.

OFICINA DE ACOGIDA DEL PEREGRINO. Estadísticas de 2016. Disponível em <https://oficinadelperegrino.com/estadisticas/> Acesso em novembro de 2019.

POLLAK, M. Memória e identidade social. Revista de Estudos Históricos. n. 5, v.10, 1992, p. 200-215.

RICOEUR, Paul. Tempo e narrativa (tomo 1). Trad. Constança Marcondes Cesar. Campinas: Papirus, 1994.

SÁNCHEZ, S. \& HESP, A. (Eds.). The Camino de Santiago in the 21st Century: Interdisciplinary Perspectives and Global Views (Vol. 5). New York: Routledge, 2015. SOUZA, Carolina; MORAES, Francilaine. Tríplice mimese de Ricoeur: modelo metodológico aplicado em narrativas sobre peregrinações. In: Atas - Investigação Qualitativa em Ciências Sociais/Investigación Cualitativa en Ciencias Sociales, v.3. 2019.

STEIL, C. A. Peregrinação, Romaria e Turismo religioso: raízes etimológicas e interpretações antropológicas. In: ABUMANSSUR. (org.). Turismo religioso: ensaios antropológicos sobre religião e turismo. Campinas: Papirus, 2003, p. 29-54.

UNESCO. World Heritage List. Routes of Santiago de Compostela: Camino Francés and Routes of Northern Spain. Disponível em <https://whc.unesco.org/en/list/669/>. Acesso em novembro de 2019. 